\title{
A construção de um curso de formação de professores na modalidade ead: conduzindo o barco entre tempestades e abrolhos
}

\author{
(The construction of a course of formation of teachers in the \\ modalidade ead: driving the boat between storms and thorns)
}

Eloiza da Silva Gomes de Oliveira

Universidade do Estado do Rio de Janeiro (UERJ) /

Faculdade de Educação Rio de Janeiro - Brasil

RESUMO: O artigo apresenta uma proposta inovadora em formação de professores, gerada pelo CEDERJ Centro Universitário de Educação à Distância - no Rio de Janeiro. O Centro Universitário foi criado através de um consórcio entre as universidades públicas sediadas no Rio de Janeiro, com o objetivo fundamental de aumentar a oferta de vagas em cursos de graduação e pós-graduação no Estado do Rio de Janeiro. A metáfora central escolhida foi a de uma viagem de barco, em que as dificuldades são comparadas aos abrolhos que podem impedir a chegada ao porto. A primeira parte do texto evidencia questões legais e conceituais em Educação à Distância (EAD), como a constituição de novos ambientes educativos, a atuação do professor nessa modalidade de ensino e a multiplicidade de recursos e possibilidades que apresenta. A segunda parte descreve a constituição e o desenvolvimento do CEDERJ, e a parceria entre duas universidades públicas (UERJ e UNIRIO), em um curso absolutamente novo: Pedagogia - Licenciatura para os anos iniciais do Ensino Fundamental.

Educação; Educação a Distância; formação de professores; educação continuada

ABSTRACT: The article presents an innovative proposal in teachers' formation, generated by CEDERJ Centro Universitário de Educação à Distância - in Rio de Janeiro. The "Centro Universitário" was created through a consortium among the headquartered public universities in Rio de Janeiro, with the fundamental objective of increasing the offer of vacancies in degree courses and masters degree in the State of Rio de Janeiro. The central metaphor was the one of a boat trip, in that the difficulties are compared to the thorns that can impede the arrival to the port. The first part of the text evidences legal and conceptual subjects in Education 
at the Distance (EAD), as the constitution of new educational atmospheres, the teacher's performance in that teaching modality and the multiplicity of resources and possibilities that it presents. The second part describes the constitution and the development of CEDERJ, and the partnership among two public universities (UERJ and UNIRIO), in a course absolutely new: Pedagogy - Formation of basic education teachers.

Education; Distance Learning; teachers' formation; continued education.

\section{INTRODUÇÃO}

Ao escolher a metáfora que intitula este texto - «entre tempestades e abrolhos» - tivemos a intenção de expressar a incerteza que sempre acompanha uma iniciativa totalmente nova, em relação à qual não temos certeza do sucesso ao final.

Como são fortes as metáforas, no entanto! Não desejo que a impressão que reste ao leitor seja a de uma experiência angustiante, ou constrangedora. Ao contrário, a coordenação do Curso de Pedagogia para as séries iniciais do Ensino Fundamental do convênio UERJ - CEDERJ, no Rio de Janeiro, é - pois ainda se encontra em processo - uma oportunidade de crescimento e de ricas aprendizagens.

Acreditamos tratar-se de uma experiência significativa a reflexão sobre a Educação a Distância nos sistemas educacionais - no nosso caso, voltada para o Ensino Superior.

Voltando à metáfora inicial do «barco» - significando no nosso caso o Projeto - ele é coletivo, e isto proporciona a segurança natural ao ato de compartilhar. Ao mesmo tempo, não possuimos a segurança de um «mapa» para a viagem, já que a iniciativa de um curso de maior duração (seis semestres) é bastante nova. Além disto, a participação em um «consórcio» formado pelas Universidades Públicas do Rio de Janeiro, de que falaremos mais adiante, trazia inseguranças naturais ao empreendimento.

Vamos contar um pouco da história dessa «viagem», focalizando principalmente as duas etapas iniciais: a constituição do CEDERJ e a elaboração coletiva do projeto do Curso de Pedagogia para as séries iniciais do Ensino Fundamental.

Neste momento, com o curso aprovado pelo Ministério da Educação e Cultura do Brasil (MEC), apresentam-se outros desafios: a realização do primeiro vestibular; o término da instalação dos pólos nos municípios do interior do Rio de Janeiro; a definição final do projeto de tutoria, entre outros.

Nesta parada, para relatar um pouco da rica experiência vivida, cabem as palavras de Eduardo Galeano, ao falar da utopia:

Janela sobre a utopia

Ela está no horizonte - diz Fernando Birri. - Me aproximo dois passos, ela se afasta dois passos. Caminho dez passos e o horizonte corre dez passos. Por mais 
A construção de um curso de formação de professores na modalidade ead: conduzindo o barco...

que eu caminhe jamais a alcançarei. Para que serve a utopia? Serve para isso: para caminhar. (Galeano, 1994. P. 310)

À moda do «sonho possível» de Paulo Freire, construído na dura realidade do cotidiano, porém firme e alegre, vamos continuar tecendo este curso, que aponta para o sonho de democratizar, no Estado do Rio de Janeiro, o acesso à Universidade gratuita. Ao mesmo tempo, busca formar, com qualidade, professores para o Ensino Fundamental, onde tudo começa, em termos da Educação Formal.

\section{O INÍCIO DO PERCURSO: A CRIAÇÃO DO CEDERJ}

Refletir sobre dois aspectos torna-se necessário, antes de falar da criação do Centro Universitário de Educação à Distância. $\mathrm{O}$ primeiro refere-se à estrutura legal que ampara as iniciativas em EAD no Brasil. A Lei de Diretrizes e Bases da Educação Nacional - LDB (Lei 9.394/96) atribui a cada Município e, supletivamente, ao Estado e à União, a incumbência de "realizar programas de formação para todos os professores em exercício, utilizando para isso também os recursos da Educação a Distância" (Art. 87, parágrafo $3^{\circ}$, inciso III), de tal modo que, até o fim da Década da Educação (ano 2006), somente sejam admitidos "professores habilitados em nivel superior ou formados por treinamento em serviço" (Art. 87 parágrafo $4^{\circ}$ ).

Isto deixa claro que, paralelamente à obrigatoriedade da formação superior para os professores, existe a definição da EAD como uma alternativa, para uma formação de tão larga escala.

O Decreto $n^{\circ} 2494$, de 10/02/98, em seu Artigo $1^{\circ}$, conceitua a Educação a Distância como:

... uma forma de ensino que possibilita a auto-aprendizagem, com a mediação de recursos didáticos sistematicamente organizados, apresentados em diferentes suportes de informação, utilizados isoladamente ou combinados, e veiculados pelos diversos meios de comunicação.

O segundo ponto refere-se às condições de acesso à Educação Superior, no nosso país. O quadro abaixo, apresentado pelo Instituto Nacional de Estudos e Pesquisas Educacionais (INEP) do Ministério da Educação e Cultura mostra claramente. Em relação ao estado do Rio de Janeiro, a dificuldade de acesso aos cursos de Graduação das Universidades públicas, e a busca - quase estabelecida como compulsória - pelas Universidades particulares.

O número de vagas oferecidas pelas Universidades Públicas (13 943 pelas federais e 5123 pelas estaduais) parece irrisório, se comparado às 129804 vagas ofertadas pelas Universidades Particulares do Estado. 
Eloiza da Silva Gomes de Oliveira

Educação Superior - Graduação

\begin{tabular}{|c|c|c|c|c|c|c|c|}
\hline \multirow{2}{*}{\multicolumn{2}{|c|}{ Estatísticas }} & \multirow{2}{*}{ Ano } & \multirow{2}{*}{ Total } & \multicolumn{4}{|c|}{ Categoria Administrativa } \\
\hline & & & & Federal & Estadual M & Municipal & Privada \\
\hline \multicolumn{2}{|l|}{ Instituições } & 2000 & 101 & 8 & 3 & - & 90 \\
\hline \multicolumn{2}{|l|}{ Cursos } & 2000 & 973 & 158 & 55 & - & 760 \\
\hline \multicolumn{2}{|l|}{ Matrículas } & 2000 & 295.9 & $93 \quad 61.663$ & $3 \quad 18.772$ & $2-$ & 215.558 \\
\hline \multicolumn{2}{|l|}{ Concluintes } & 1999 & 35.468 & 8.355 & 2.299 & - & 24.814 \\
\hline \multicolumn{2}{|c|}{ Funções Docentes em Exercício } & 2000 & 24.723 & 6.956 & 2.820 & - & 14.947 \\
\hline \multicolumn{2}{|c|}{$\begin{array}{l}\text { Funcionários Técnico- } \\
\text { Administrativos em Exercício }\end{array}$} & 2000 & 26.007 & 11.635 & 1.591 & - & 12.781 \\
\hline \multirow[t]{3}{*}{ Vestibular } & Vagas Oferecidas & 2000 & 148.870 & 13.943 & 5.123 & - & 129.804 \\
\hline & Inscrições & 2000 & 435.981 & 151.278 & 136.040 & - & 148.663 \\
\hline & Ingressos & 2000 & 90.795 & 13.681 & 5.132 & - & 71.982 \\
\hline
\end{tabular}

Fonte: MEC/INEP

O fato de haver, no Rio de Janeiro, um significativo número de pessoas excluídas do processo educacional, levou o Governo do Estado, através da Secretaria de Estado de Ciência e Tecnologia (SECT) a implementar a política de utilização do Ensino à Distância.

A dificuldade de deslocamento de alunos dos municípios do interior para os grandes centros, alia-se à pequena oferta de vagas em cursos de Graduação nesses municípios e à carência de professores para essas áreas.

Tudo isto gerou uma demanda quase explosiva de formação continuada, para a qual o Governo do Estado precisava responder. Isto se deu, em 1999, através de um consórcio entre as universidades públicas sediadas no Estado (UERJ, UNIRIO, UENF, UFRJ, UFF e UFRRJ).

O CEDERJ - Centro Universitário de Educação a Distância do Estado do Rio de Janeiro - foi resultado de um ano de trabalho conjunto entre a SECT e as universidades tendo como objetivos, segundo os documentos do próprio CEDERJ:

D contribuir para a interiorização do ensino superior gratuito e de qualidade no Estado do Rio de Janeiro;

D facilitar o acesso ao ensino superior daqueles que não podem estudar no horário tradicional;

D atuar na formação continuada à distância de profissionais do Estado, com atenção especial ao processo de atualização de professores da rede estadual de ensino médio; 
A construção de um curso de formação de professores na modalidade ead: conduzindo o barco...

D aumentar a oferta de vagas em cursos de graduação e pós-graduação no Estado do Rio de Janeiro.

A estratégia da EAD, mantendo a reconhecida qualidade dos cursos oferecidos pelas universidades consorciadas, impôs-se de imediato e constituiuse em um desafio para os participantes do processo.

Considerando as experiências bem sucedidas com cursos de Graduação à distância, desenvolvidas em vários países, o CEDERJ prevê a criação de 21 pólos, em diferentes municípios do Estado do Rio de Janeiro. Neles serão oferecidos múltiplos recursos como salas de estudo, microcomputadores conectados à Internet, multimeios, videoconferências, supervisão acadêmica, biblioteca, recursos audiovisuais, seminários presenciais e distribuição de material didático, além de realizados os exames presenciais..

As Universidades Consorciadas participam com o registro acadêmico dos alunos, a definição dos currículos, a elaboração dos conteúdos do material didático, a realização da tutoria a distância, a orientação acadêmica, a avaliação dos alunos nas formas presencial e à distância e a emissão dos diplomas.

\section{O CURSO DE PEDAGOGIA PARA AS SÉRIES INICIAIS DO ENSINO FUNDAMENTAL: O PORTO ALMEJADO PELA «VIAGEM»}

A crescente demanda pelas vagas na Universidade Pública, somada aos outros fatores citados, fez com que o Grupo de Trabalho formado por professores da UERJ e da UNIRIO, instituições parceiras neste empreendimento, enfrentasse com disposição a construção do projeto do curso citado no título desta seção.

Entendendo que as modalidades de ensino presencial e a distância não são mutuamente exclusivas, mas complementares, optamos por uma modalidade semi-presencial de curso, com a frequência do aluno ao pólo - para o contato com o tutor local - uma vez por semana.

Foram consideradas prioritárias, nesse momento, as premissas estabelecidas pelo Plano Nacional de Graduação, proposto pelo Ministério da Educação e Cultura (MEC), que estabelece para os cursos de Graduação a distância:

D A ampliação das possibilidades de acesso ao conhecimento e aos bens culturais.

D A flexibilização no acompanhamento e estruturação do processo de estudo. A organização do tempo e dos horários dedicados ao estudo são adaptados às circunstâncias individuais, de acordo com o ritmo e o tempo interior de cada um.

D A organização precisa e o planejamento detalhado de cada etapa do processo. 
D A interação no processo de estudo, tanto no intercâmbio com outros alunos quanto no diálogo com professores e tutores.

O Plano indica a EAD como

«... um recurso que as universidades deverão considerar para satisfazer as amplas e diversificadas necessidades de formação e qualificação profissional. No contexto do ensino de graduação, deve ser pensada a partir de um projeto políticopedagógico adequado. É importante ter presente que a EAD se apresenta como mais uma alternativa para a atuação e integração das Universidades nos contextos nacional e regional.»

Podemos afirmar, então, que a Graduação na modalidade a distância atende «um outro público, constituído por aqueles que, tendo deixado a Universidade, desejam continuar se aperfeiçoando, num processo de educação continuada.»

Os indicadores de qualidade apontados pelo MEC, para a autorização de cursos de graduação a distância, também foram considerados com atenção. Sem terem a força de uma lei, eles visam «orientar alunos, professores, técnicos e gestores de instituições de ensino superior que podem usufruir dessa forma de educação ainda pouco explorada no Brasil e empenhar-se por maior qualidade em seus processos e produtos».

Sem entrar na polêmica discussão das questões da qualidade nos cursos, afirmamos a importância da continua melhoria na criação, aperfeiçoamento, divulgação de conhecimentos culturais, científicos, tecnológicos e profissionais que contribuam para superar os problemas regionais, nacionais e internacionais e para o desenvolvimento sustentável dos seres humanos, sem exclusões, nas comunidades e ambientes em que vivem.

Os dez indicadores formulados assentam-se em um princípio fundamental: o de que «não se trata apenas de tecnologia ou de informação, o fundamento da graduação é a educação da pessoa para a vida e o mundo do trabalho».

São eles:

1. integração com políticas, diretrizes e padrões de qualidade definidos para o ensino superior como um todo e para o curso específico;

2. desenho do projeto: a identidade da Educação a Distância;

3. equipe profissional multidisciplinar;

4. comunicação / interatividade entre professor e aluno;

5. qualidade dos recursos educacionais;

6. infra-estrutura de apoio;

7. avaliação de qualidade contínua e abrangente; 
A construção de um curso de formação de professores na modalidade ead: conduzindo o barco...

8 convênios e parcerias;

9. edital e informações sobre o curso de graduação a distância;

10. custos de implementação e manutenção da graduação a distância.

A estes, o Grupo de Trabalho somou alguns outros indicadores, específicos e característicos do curso em tela, e por isso não menos importantes.

O primeiro diz respeito à questão metodológica, e se impõe como de grande expressão, principalmente se entendermos metodologia como algo muito mais amplo que uma simples listagem de métodos ou de «passos formais» de ensino, que muito mais engessam que orientam os procedimentos docentes.

Considerando a crise paradigmática que a Ciência atravessa atualmente, propusemos um curso que almeja ultrapassar os limites da modernidade, baseando-se em práticas tecnológicas que ofereçam as condições de construção dos conteúdos essenciais para o domínio das ciências básicas que orientam o processo pedagógico. Este processo se origina da prática cotidiana, orientandose para possibilitar ao profissional da Educação a consolidação da mesma, através de aprofundamentos teóricos cuja função será aprimorar a prática e promover o sucesso da aprendizagem significativa dos alunos.

O segundo aponta para o foco central desta proposta de formação continuada de docentes. Therrien \& Therrien (2000, p.43) propõem que iniciativas deste teor sejam voltadas para o trabalho docente

"... concebido enquanto processo de interação. A interação social, abordada para além da linguagem, pressupõe uma forma de atividade onde sujeitos atuam em função uns dos outros, orientados por finalidades de consenso.»

Neste projeto, uma das finalidades é a reformulação do pensamento sobre o significado e o propósito da formação do professor para as séries iniciais, profissional responsável pelo início da vida acadêmica do futuro cidadão. Para isto, o processo ensino - aprendizagem previsto para o curso compreende cinco etapas fundamentais: a reflexão sobre a prática, a articulação das diversas áreas do conhecimento, a reformulação das práticas cotidianas, a formulação de um projeto político - pedagógico e a participação ativa na rede virtual de formação continuada.

O terceiro é o marco teórico construtivista, e o leque de abordagens que o compõem. Deheinzelin (1996, p.20) diz que:

«A criação de uma metodologia pedagógica construtivista tem como objetivo central a promoção do encaixe significativo entre o desenvolvimento cognitivo e a aprendizagem de conteúdos.»

Dentro deste marco buscamos em Jean Piaget (1970) dois conceitos fundamentais: 
D de equilibração cognitiva, processo dinâmico de comportamento auto - regulado, que harmoniza dois processos polares, porém complementares em sua essência - a assimilação e a acomodação. Enquanto a primeira permite a organização de novas experiências com nossas próprias estruturas mentais; a segunda permite que as pressões do ambiente, no sentido do novo, sejam elaboradas através da criação de esquemas mentais inéditos.

D de autonomia, estudado exaustivamente pelo autor no que se refere à moralidade e à cognição. A evolução dos esquemas mentais, como foi destacado acima, permite uma construção progressiva do conhecimento de forma funcionalmente contínua, porém estruturalmente descontínua. Isso permite ao indivíduo a progressiva ampliação das operações mentais, que evoluem em abrangência, grau de generalização, abstração, possibilidades de acesso e utilização dos conceitos construídos.

Uma das características fundamentais do construtivismo, ainda segundo Piaget tem sido sua postura em estabelecer a relação que o sujeito e o objeto mantêm entre si no ato de conhecer. Sua convicção fundamental é a de que os conhecimentos resultam de uma construção ; eles constituem, pois, uma construção contínua de estruturas novas, comandadas pelo imperativo da interdisciplinaridade. $\mathrm{O}$ construtivismo constitui, portanto, um projeto essencialmente interdisciplinar que visa estabelecer a estreita vinculação entre ensino e pesquisa

O curso empreende uma revisão do processo educativo, propondo-se a descobrir novos espaços para a aprendizagem a distância. Pretende-se que a metodologia para EAD permita os espaços da necessária «desequilibração cognitiva», estimulando o processo de adaptação, tornado sinônimo, por Piaget, da aprendizagem..

Continuando o delineamento da base teórica, podemos afirmar que um curso como este, voltado para a formação de professores, deve possuir como um de seus propósitos a autoformação, pois a autonomia do indivíduo - em seu sentido pleno - é um compromisso de todo o processo educativo.

Desta forma, os materiais pedagógicos produzidos devem estar acessíveis, ser de fácil consulta, apresentar o professor progressivamente ao conhecimento, à compreensão, à análise e aplicação do conteúdo a ser trabalhado. Ao mesmo tempo, porém, deve ser desafiador e propor "problemas» vinculados à realidade da prática docente.

Pretende-se, assim, despertar a motivação pela educação continuada, necessária ao professor e aos demais profissionais. Este tipo de formação pode ser conceituada, como o faz Candau (1997), como a formação em serviço, as atividades de formação continuada realizadas no próprio local do trabalho 
A construção de um curso de formação de professores na modalidade ead: conduzindo o barco...

escolar, além de outras atividades, organizadas por instâncias superiores dos sistemas de ensino, e oferecidas aos profissionais que deles já fazem parte.

Em Vygotsky $(1978,1998)$ encontramos um leque conceitual muito rico, do qual selecionamos três conceitos que julgamos importantes:

D de interação social, um dos focos da obra do autor, que enfatiza a dialética entre o indivíduo e a sociedade, o intenso efeito da interação social, da linguagem e da cultura, sobre o processo de aprendizagem. Este processo é fundamental para a interiorização do conhecimento - ou transformação do conceitos espontâneos em científicos - através do processo de tornar intrapsíquico o que antes era interpsíquico.

D $\mathrm{O}$ conceito de zona de desenvolvimento proximal, espaço onde atua o processo de aprendizagem, através de atividades realizadas com a ajuda do «outro significativo» mais capaz naquele aspecto. Segundo Fosnot (1998) é nessa zona que "os conceitos científicos trabalham de forma descendente, enquanto os conceitos espontâneos trabalham de forma ascendente» (pp. 356). Este entrelaçamento, junto com a conotação ideológica transmitida na relação de ajuda, faz com que o desenvolvimento potencial seja convertido em real.

D conceito de mediação, abordado por Vygotsky como mediação semiótica e como domínio de si.. Ao contrário das ferramentas físicas, que se orientam para uma ação sobre o mundo externo, as ferramentas semióticas - como a linguagem, por exemplo - dirigem-se para o mundo social, para os outros indivíduos. Nesta forma de mediação, como bem apresenta Baquero (1998):

"O domínio crescente das ferramentas culturais define de algum modo as fases de formação de um sujeito cultural.(...) o uso interiorizado delas, possibilitando um controle maior e regulação sobre as operações psicológicas próprias». (p. 40)

Utilizando ferramentas semióticas, o homem se apropria ativamente do conhecimento, articulando as duas formas de mediação descritas. Constituem-se, assim, a intersubjetividade e também a subjetividade.

A metodologia proposta pelo curso em tela constitui-se em uma nova forma de mediação, não prevista pelo autor. Utilizando-se de novas ferramentas / linguagens, ocorre o que Lévy chamou de «mediação digital», remodeladora de atividades cognitivas fundamentais. Segundo ele,

" ...a sensibilidade, o conhecimento e a imaginação musical, a visão e a elaboração de imagens, a concepção, a perícia, o ensino e o aprendizado, reestruturados por dispositivos técnicos inéditos, estão ingressando em novas configurações sociais.» (1998, p.16-7) 
As novas tecnologias, assim compreendidas, arejam as relações pedagógicas, a fim de que passem a oferecer um quadro ampliado quanto ao «uso da máquina» . O usuário deve ser incentivado a superar desafios, buscando sempre articular novas possibilidades a conhecimentos anteriores. Ainda segundo Lévy (op. cit., p. 27), o professor passa a ser um «animador de aprendizado», ou seja, a pessoa que irá contribuir para o efetivo exercício da interdisciplinaridade, nos moldes de uma escola construtivista. É importanmte, no entanto, que isto não se confunda com a atuação do tão conhecido "facilitador da aprendizagem», proposto pela Escola Humanista, pelo paradigma subjetivista, em Psicologia e em Educação.

Por tudo que foi exposto, podemos considerar que o conceito de ambiente educativo ampliou-se consideravelmente hoje em dia, através das novas tecnologias de comunicação e informação .

O curso proposto pode utilizar-se de uma variedade de meios de EAD aplicando, concretamente, os princípios teóricos que apresentamos acima.

Assim, na escola demandada pela sociedade informática, a informação só faz sentido se diretamente associada à construção do conhecimento, numa perspectiva construtiva, que faculta comportamentos de transferência de conhecimentos e habilidades. Trata-se da ampla competÇência de «aprender a aprender», de que tanto se fala atualmente. Essa deve ser uma perspectiva de Educação presente em todas as esferas do ensino formal.

O quarto e último indicador refere-se ao perfil de educador que este curso pretende formar.

Como diz o documento do Projeto do Curso de Pedagogia para as séries iniciais do Ensino Fundamental do CEDERJ (2001):

«Pretende-se uma formação do educador articulada com diferentes situações de trabalho do profissional - como professor, educador e pesquisador -, formação essa capaz de analisar e criticar os problemas da prática pedagógica e de intervir e aperfeiçoar as propostas educativas nos diferentes campos da educação formal e não-formal. Sustenta-se que um pedagogo bem qualificado deve ser capaz de interagir no mercado de trabalho, na sua comunidade, na sociedade como um todo, de forma crítica e participativa, tendo como meta contribuir para o desenvolvimento da cidadania plena.»

O Curso está estruturado em quatro grandes áreas de conhecimento, a saber: Fundamentos, Linguagens, Ciências Sociais, Ciências Exatas e da Natureza, contemplando a construção de uma prática docente, alicerçada na compreensão de elementos conceituais relacionados ao processo ensino-aprendizagem, através de três eixos norteadores - HOMEM, SOCIEDADE e TRANSFORMAÇÃO - integradores das grandes áreas e das disciplinas que compõem o curso, procurando ampliar os fundamentos das práticas já existentes no trabalho cotidiano de cada professor. 
A construção de um curso de formação de professores na modalidade ead: conduzindo o barco...

A estrutura curricular deverá permitir que o aluno consiga, desde o primeiro período e a partir de sua prática docente, encontrar nos Fundamentos da Educação (Psicologia, Filosofia, História e Sociologia da Educação) subsídios para uma reflexão desta prática e a ela retorne com o espírito investigativo, crítico e reflexivo da pesquisa, objetivando a construção coletiva do Projeto Pedagógico para a sua escola.

Estes Fundamentos não são separados por área de conhecimento, mas oferecidos, de forma interdisciplinar, nos quatro primeiros períodos do curso.

Outra inovação constitui-se no fato da Prática de Ensino ser iniciada já no segundo período do curso. O aluno começa conceituando-a, e chegará - nos últimos períodos - a discutir as transformações do cotidiano no espaço escolar e as diversas práticas que possibilitam o processo ensino - aprendizagem, além de estabelecer relações entre os saberes agregados e a prática pedagógica, diferenciada segundo os contextos de prática / estágio oferecidos para desenvolver o processo de ensino - aprendizagem. Pretende-se que ele chegue a uma construção da própria prática, numa metodologia que inclui a WEB como forma de ensino e possibilita a análise do ciclo pedagógico desde o planejamento até a avaliação .

A Pesquisa e a Prática Pedagógica são estruturadas sob a forma de disciplinas, oferecidas nos seis semestres do curso,

sobretudo através da reflexão individual e coletiva a respeito das muitas possibilidades de intervenção, sempre associadas ao contexto específico no qual os problemas se apresentam.

Os conteúdos dessas disciplinas servirão de suporte para que os alunos desenvolvam o seu potencial de intervenção no cotidiano das escolas e na construção e na execução dos Projetos Político - Pedagógicos das mesmas.

A avaliação da aprendizagem dos alunos deve compreender, no mínimo, exercícios avaliativos, duas avaliações a distância, duas avaliações presenciais e, quando necessário, uma avaliação suplementar presencial, como mostra o esquema abaixo:

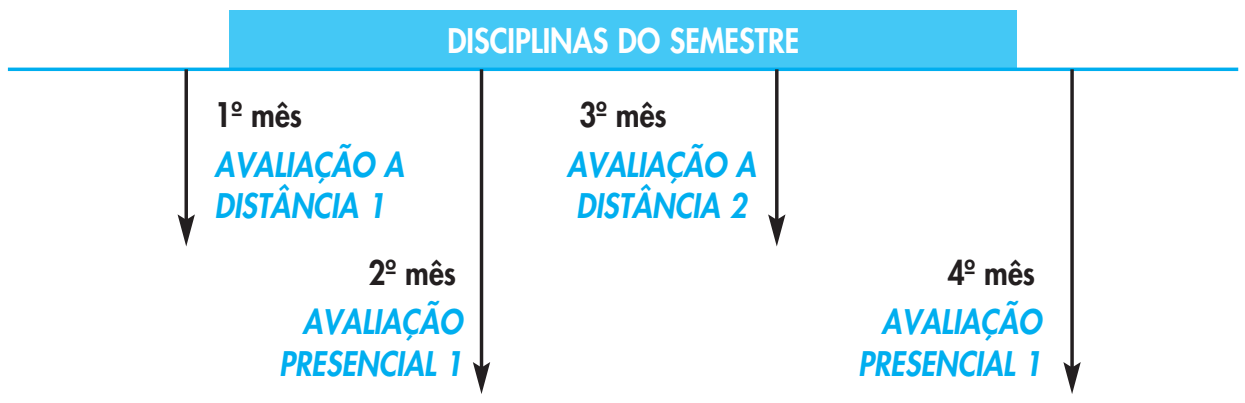


Os exercícios avaliativos (EA) são exercícios pertinentes às unidades didáticas. No final do caderno didático, correspondendo ao final de cada aula, haverá um conjunto de EA. A idéia fundamental é que o aluno do CEDERJ possa auto-avaliar - se no acompanhamento da disciplina (testes sem notas).

As avaliações a distância (AD) são de caráter formativo e devem ser realizadas no final do primeiro e do terceiro meses. A estas avaliações devem ser atribuídas notas. A sugestão é que o peso de cada avaliação a distância corresponda a $10 \%$ (dez por cento) da nota final do aluno na disciplina. Assim, a soma dos resultados das AD corresponderá a $20 \%$ da nota final.

Sempre que possível, essas avaliações devem conter trabalhos ou questões a serem resolvidas por grupos de alunos, estimulando o processo cooperativo de aprendizagem e de solução de problemas..

As avaliações presenciais (AP) devem ser aplicadas no final do segundo mês e do período letivo ( fim do quarto mês). Essas avaliações têm, no entanto, planejamento temporal rígido. Realizadas nos pólos regionais ou nas universidade consorciadas, devem ocorrer em dias e horários preestabelecidos, dentro dos Períodos de Avaliações Presenciais, sendo duas por semestre letivo, com duração aproximada de uma semana cada, planejadas e incluídas no calendário escolar (publicado no Manual do Aluno CEDERJ). Recomenda-se não haver qualquer outra atividade letiva durante esses períodos.

Tais avaliações devem seguir o padrão próprio dos exames presenciais realizados pelas Universidades Consorciadas, tanto no que se refere à fiscalização, quanto à elaboração, aplicação e correção das provas. O padrão de excelência do CEDERJ corresponderá à qualidade de suas AP. Sugere-se que o peso de cada avaliação presencial (AP) seja de $40 \%$ (quarenta por cento) do total da nota final. Assim, as avaliações presenciais, somadas, corresponderiam a $80 \%$ (oitenta por cento) da nota final do aluno.

A avaliação suplementar presencial (ASP) deve acontecer um mês após a última avaliação presencial. Constitui-se em uma segunda chance para o aluno que não obteve aprovação nas avaliações anteriores.

O Centro Universitário de Educação à Distância deverá manter-se em constante processo de aprimoramento, tanto no que se refere ao adequado funcionamento, como na procura do alcance social de suas ações. Isso demanda que a Instituição seja permanentemente avaliada quanto ao mérito (qualidade interna de recursos e funcionamento) e à relevância (resultado, impacto e repercussões) das atividades praticadas pelo consórcio.

O documento do Projeto do Curso de Pedagogia para as séries iniciais do Ensino Fundamental do CEDERJ (2001) prevê quatro tipos de procedimentos: 
A construção de um curso de formação de professores na modalidade ead: conduzindo o barco...

D Banco de dados institucionais - será criado um banco de dados com informações institucionais, constantemente atualizado, visando agregar elementos para uma análise do funcionamento do curso;

D Avaliação de cursos e disciplinas - alunos e professores realizarão, periodicamente, avaliações das disciplinas, infra-estrutura e outros aspectos importantes do curso. A cada semestre os alunos e docentes responderão a um questionário eletrônico de avaliação contendo perguntas referentes a cada disciplina, assim como um grupo de outras perguntas de caráter geral.

As informações coletadas serão apresentadas às comunidades interna e externa na forma de relatórios comparativos;

D Avaliação institucional permanente - será implementado um processo anual em que os diversos atores da Instituição (docentes das Universidades Consorciadas, tutores, funcionários técnico-administrativos e alunos) utilizarão, para uma análise qualitativa, os diversos elementos coletados ao longo do ano, com o objetivo de elencar um conjunto de sugestões de melhoria da qualidade do trabalho da Instituição.

D Processo on-line de correção de problemas - será construído um procedimento informatizado para detectar falhas no funcionamento da estrutura, especialmente no que concerne aos processos de tutoria, distribuição de material didático e aplicação e correção dos exames presenciais e a distância. Além disso, os alunos e tutores serão incentivados a utilizar o sistema sempre que necessário. Com esta ação, pode-se obter a imediata correção de rumos, evitando evasão decorrente de problemas inerentes ao funcionamento interno do curso.

\section{PRÓXIMOS DO PORTO - O ESTÁGIO ATUAL DO PROJETO}

Atualmente, aprovado nas instâncias internas das duas Universidades UERJ e UNI-RIO - e, em caráter inicial, pelo Ministério da Educação - o curso encontra-se em fase de elaboração das aulas.

Os professores - conteudistas (em duplas, incluindo um professor de cada uma das Universidades citadas) constróem as aulas das disciplinas que, passando por revisores especializados em EAD, vão sendo formatadas em material impresso e, logo a seguir, convertidas para ambientes virtuais.

Como se trata de um curso a ser implantado em municípios muitas vezes distantes, consideramos que a existência do material impresso é indispensável, e poderá suprir eventuais dificuldades de acesso à Internet. 
Revisitando a metáfora com que iniciamos este texto, lembramos que é justamente perto da praia que muitas vezes os abrolhos se localizam, dificultando a chegada do nosso «barco - projeto» ao porto pretendido.

Pretendemos superar os obstáculos naturais, fazendo mais do que apenas treinar professores, mas desenvolver uma verdadeira formação continuada.

Aquela que, no dizer de Pedro Demo (1998), leva o professor a «aprender a pesquisar, pois é a pesquisa que mais lhe define o exercício profissional» (p. 182).

Desta forma poderemos, através da democratização do acesso à educação continuada propiciada pela Educação a Distância, prover as escolas de professores solidamente formados, pesquisadores críticos e reflexivos. 
A construção de um curso de formação de professores na modalidade ead: conduzindo o barco...

\section{REFERÊNCIAS BIBLIOGRÁFICAS}

Baquero, Ricardo (1998). Vygotsky e a Aprendizagem Escolar. Porto Alegre: Artes Médicas.

BRASIL. Lei de Diretrizes e Bases da Educação Nacional. Lei 9394 de 23 de dezembro de 1996

- Decreto $n^{\circ}$ 2494, de 10/02/98. Regulamenta o Art. No 80 da Lei de Diretrizes e Bases da Educação Nacional.

CANDAU, VERA .M. (1997). Magistério - Construção cotidiana. Petrópolis: Vozes.

Deheinzelin, monique (1996). Trilha - Educação e Construtivismo. Petrópolis: Vozes.

Demo, Pedro (2000). Questões para Teleducação. Petrópolis: Vozes.

Fosnot, Catherine Fomey (1998). Construtivismo: Teoria, Perspectivas e Práticas. Porto Alegre: Artes Médicas.

Galeano, Eduardo (1994). As Palavras Andantes. Porto Alegre: L\& PM,

Governo Do Estado de Rio de Janeiro / SECT. (2001). Pedagogia dos anos iniciais do Ensino Fundamental. Curso do Convênio UERJ / CEDERJ, (mimeo).

LÉvy, Pierre (1998). A Máquina Universo. Porto Alegre: Artes Médicas.

Piaget , Jean (1970). Ëpistemologie des sciencies de lhomme. Paris: Gallimord.

Therrien, Jacoues \& Therrien, Angela T. S. (2000). Cultura docente e gestão pedagógica: a racionalidade prática dos saberes do saber-fazer. Tecnologia Educacional. 29 (150/151), $42-51$

VyGotsky, L. S. (1978). Mind in society : the development of higher psychological processes. Cambrige: Harvard University Press.

- (1998). Pensamento e linguagem. São Paulo: Martins Fontes.

\section{PERFIL ACADÊMICO E PROFISSIONAL}

Eloiza da Silva Gomes de Oliveira es doutora em Educação e Mestre em Psicologia Escolar, Vice-Diretora da Faculdade de Educação da Universidade do Estado do Rio de janeiro (UERJ).

Pesquisadora nas área de Avaliação e de Representações Sociais

Endereço: Rua General Espírito Santo Cardoso, 350, casa 11. Tijuca, Rio de Janeiro, RJ, Brasil. CEP: 20530-500. Fones: (21) 2238-1280 e (21) 9953-5332.

Endereço electrônico: eloizagomes@hotmail.com. 